\title{
LA JUVENTUD DEL 98 EN LAS REVISTAS DE LA ÉPOCA
}

\section{YOUTH OF 98 IN THE MAGAZINES OF THE TIME}

\section{AUTORES}

\section{Manuel A. Espegel Vallejo}

Profesor de Ingeniería Naval de Universidad Politécnica de Madrid (España)

ma.espegel@upm.es

\section{María Luisa García Ochoa}

Directora de la Biblioteca de la Facultad de Ciencias de la Información de la Universidad Complutense de Madrid (España)

ochoa@buc.ucm.es

\section{RESUMEN}

La comercialización de la prensa supone una difusión del conocimiento social y de la cultura, y se convierte en el principal vehículo de éstos. El libro, tras la prensa, pasó a un segundo plano. La Generación del '98 utilizó la prensa para reflejar su ideología y permitir al pueblo conocer sus opiniones, sumamente influyentes en el momento. La prensa se convierte en el principal vehículo de la cultura, la información y la ideología popular.

\section{PALABRAS CLAVE}

Modernismo - Generación del '98 - Ideología - Prensa - Vehículo informativo 


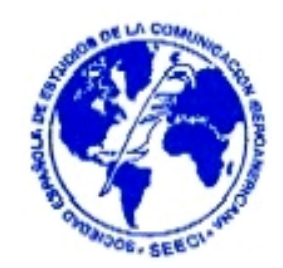

\section{ABSTRACT}

The commercialization of the press is a social diffusion of knowledge and culture, and becomes the main vehicle for these. The book, after the press went into the background. The Generation of ' 98 used the press to reflect their ideology and enabling people to make their views known, highly influential at the time. The press becomes the main vehicle of culture, information and popular ideology.

\section{KEY WORDS}

Modernism - Class of '98 - Ideology - Press - Vehicle Information

\section{ÍNDICE}

1. Introducción.

2. Modernismo y 98.

3. La política y el problema de España.

4. Bibliografía.

\section{Introducción.}

Los últimos años del siglo pasado y los primeros del nuestro, vieron el nacimiento de un numeroso grupo de revistas, en las que comienzan a aparecer las firmas de los hoy llamados "componentes de la Generación del 98". Su estudio, cien años después y desde la perspectiva actual, revela lo que supuso el movimiento ideológico y 


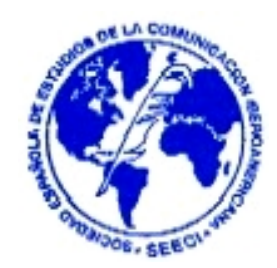

estético que emergía. En efecto, en sus columnas se esconden los escritos incipientes de las plumas que poco después destacarán como figuras literarias, y es a través de ellas donde posiblemente se fue forjando el concepto de "Generación", hoy tan discutido. Los títulos más representativos de estas revistas, cuya vida ha sido casi siempre breve, fueron principalmente: Germinal, Vida Nueva, Revista Nueva, Electra, Juventud, Alma Española, La República de las Letras y Quiz Helios.

Nos parece importante recordar que, en este gozne que el año 1898 supone, la prensa se había logrado convertir en el vehículo fundamental de difusión del conocimiento social y de la cultura, hasta tal punto de desbancar al libro de su tradicional puesto. Unamuno se queja en 1904 de lo poco conocidos que son sus libros mientras que sus artículos de prensa tenían todo un reconocimiento de su labor intelectual, como señala María de Pilar Palomo. De hecho, muchos de los libros de los noventayochistas surgen como complicaciones de los artículos que durante estos años publicaron en estas revistas y en la prensa en general. Mediante la prensa, medio que llega a un gran público, estos pensadores intentan poner en práctica el impulso crítico y esperanzador que surge en la etapa previa dentro del llamado "espíritu regeneracionista". Como reconocerá Unamuno más tarde, era el único órgano de opinión pública en España: "La prensa ha hecho que el pueblo se haga pueblo" y "es la que más ha contribuido a hacer conciencia popular nacional" (Hay que enterarse, en el Sol, 15-5-1932, tomado de Palomo).

Por tanto, la génesis y el desarrollo de los distintos movimientos culturales y estéticos de final de siglo se van a plasmar en el periódico, como cauce de información cotidiana, y sobre todo, en la revista, con un objetivo más especializado. Aunque nuestros hombres escriben una ingente producción en los periódicos de la época Unamuno declarará (como recoge Marcelino Tabajas) que prefería "escribir en una revista, y no en un diario, porque en éstos, en unos por unas razones y en otros por las contrarias, no goza de verdadera libertad un colaborador sincero". En efecto, esta libertad con la que escribieron en las revistas se contrapuso en ocasiones a la actitud con la que opinaron en los diarios, autodenominados como "independientes". 


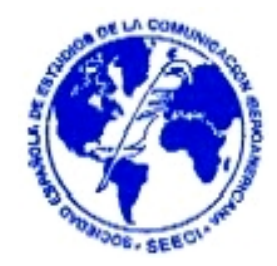

Aunque todos tenían su propia ideología e incluso dependían de orientaciones partidistas concretas, los diarios eran respetuosos con las instituciones y sus colaboradores debían resignarse a este principio, "resignados a la tiranía del que paga". El interés por estas revistas se debe, en primer lugar, a la libertad de la que gozaron sus escritores y, en segundo lugar, a su capacidad para anticipar y retratar el espíritu de grupo que emerge dentro de un movimiento histórico. Este aspecto fundamental que hace de la revista una fuente de conocimiento esencial ha sido puesto de relieve por Guillermo de Torre, con palabras que merece la pena que reproduzcamos:

"...el perfil más neto de una época, el esguince más revelador de una personalidad, el antecedente olvidado o renegado de cierta actitud que luego nos asombra, en tal o cual escritor, se hallan escondidos, subyacentes, no en los libros, sino en las páginas de las revistas principales. Aun más, suele acontecer que el escritor si es enterizo, genuino, está ya performado en aquéllas; allí aparece su imagen quizá imperfecta, pero más pura y sincera, en su primer hervor". Las revistas, para él "son más atrayentes, pródigas y reveladoras". Tienen... el encanto de lo fragante e inmaduro. Frente al destino egoísta de cada libro, poseen la supremacía de su condición plurar y generosa, como fruto que son de un grupo, de un esfuerzo colectivo (...). Son los boletines metereológicos que anuncian con precisión infalible cada nuevo salto en la rosa de los tiempos del espíritu (...). Todo movimiento literario, todo amanecer, todo crevar de albores por decirlo con la imagen matinal del Cantar del Mío Cid, ha tenido indefectiblemente su primera exteriorización en las hojas provocativas de alguna revista (...) La revista anticipa, presagia, descubre, polemiza (...) La revista es vitrina y es cartel. El libro ya es, en cierto modo, un ataúd".

La gran cantidad de títulos que aparecen en este momento es síntoma que revela, 


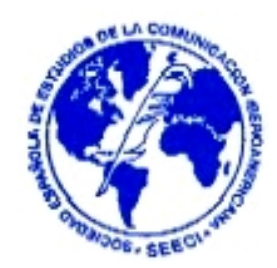

como apunta Seoane, una gran vitalidad pero, al mismo tiempo, una gran precariedad: "una vida efímera, brillante y loca", en palabras de Manuel Machado. Y sería erróneo pensar que dichas revistas aparecen a partir de la guerra y como consecuencia del desastre: existen con anterioridad una corriente crítica que no es sino manifestación de la misma crisis que desembocará en el Desastre. Como apuntó Azorín en artículos publicados en $A B C$ (febrero de 1913, recogidos por Palomo):

"Se cree generalmente que toda esa bibliografía regeneradora, que todos esos trabajos formados bajo la obsesión del problema de España, han brotado a raíz del desastre colonial y como consecuencia de él. Nada más erróneo; la literatura regeneracionista, producida de 1898 hasta años después, no es sino una prolongación, una continuación lógica, coherente, de la crítica política y social que desde mucho antes de las guerras coloniales venía ejerciéndose".

Y es precisamente este pensamiento crítico de los intelectuales regeneracionistas sobre todo, que trataban de forjar una nueva idea de España basada en la autenticidad, el que aparece en algunas de las revistas que anteceden a las del 98, y que podemos considerar por tanto como sus precedentes (recordamos ahora el poder anticipador de la revista). Tal es el caso de la Revista Contemporánea, fundada en 1875 (duró hasta 1907) por José del Perojo, que conectó profundamente con el regeneracionismo. Gran prestigio tuvo también durante los años de la Regencia La España Moderna (1889-1914). Fundada por Lázaro Galdeano, pretendía representar en nuestro país lo que las Revue de Deux Mondes en el vecino. Y también citaremos la revista Nuevo Teatro Crítico, con Emilia Pardo Bazán prácticamente como única autora, en la que expuso desde sus teorías literarias hasta su pensamiento, marcado por el europeísmo y un sincero feminismo.

Es interesante conocer la edad y el momento creador que tenía esta "juventud" en 1898. Unamuno era el mayor, tenía 34 años, y ya había publicado artículos de "En torno al casticismo" y "Paz en la guerra". Ganivet con un año menos, 33, se suicidó 


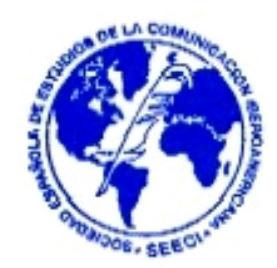

ese mismo 1898. Después le seguían en edad Valle-Inclán con 29 y Baroja, con 26, que iniciaba sus contactos con el mundo literario. Martínez Ruíz (Azorín desde 1904), con 25 años, intentaba abrirse camino en el mundo del periodismo, aunque ya había colaborado en algún periódico. Maeztu tenía 24 años y los artículos que fue publicando se presentarán en forma de libro en 1899. Antonio Machado, con 23 años, había empezado a colaborar en el diario El País. Otras figuras como Blasco Ibáñez, que pudiera haber figurado como noventayochista por su ideología aunque de estética realista, contaba con 31. Juan Ramón Jiménez contaba sólo con 17 años, le quedaban todavía tres para llegar a Madrid para "luchar por el modernismo". Mientras, la generación anterior de escritores, con la que se enfrentaron y a menudo polemizaron, estaba distante en edad: Valera, 74; Pereda, 65; Galdós, 55; Emilia Pardo Bazán, 47 y Clarín, 46.

\section{Modernismo y 98.}

La crítica ha separado en ocasiones el modernismo de la llamada "generación del 98". Un ejemplo fue Salinas, que matizaría más tarde su opinión. Desde nuestro punto de vista, y después del estudio de las revistas analizadas, resulta imposible separar la crítica social característica de la generación del 98 del movimiento renovador de la nueva estética modernista. Sólo a partir de la consideración del modernismo como un movimiento literario y cultural de amplio espectro dentro del cual aparece la generación del 98, se puede entender este fenómeno y los autores que lo integraron. Así lo expresa Onís en el prólogo a su conocida Antología de la poesía:

"El modernismo es la forma hispánica de la crisis universal de las letras y del espíritu que inicia hacia 1885 la disolución del siglo XIX, y que se había de manifestar en el arte, la ciencia, la religión, la política y gradualmente en todos los demás aspectos de la vida entera, con todos los caracteres, por lo tanto, de un hondo cambio 


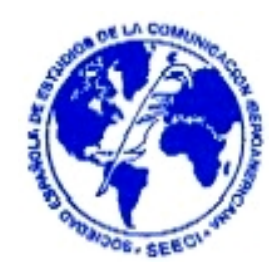

histórico cuyo proceso continúa hoy".

Esta crisis espiritual va a repercutir en el concepto del arte, como manifestará Juan Ramón Jiménez más tarde en una entrevista publicada en La Internacional en 1920 y que ha sido reproducida recientemente en El País (12 de abril de 1998). Reivindica la sensibilidad y la espiritualidad para transformar una sociedad que evitaría así las guerras:

"...el arte tiene una misión social, indirecta, como toda misión honrada y fructífera: la de hacer verdaderamente fuertes -quiero decir delicados- a los hombres, y verdaderamente buenos, esto es, enamorados conscientes de la tierna belleza desnuda del mundo".

Quizá la mejor definición del modernismo fue acuñada por Juan Ramón y publicado en el periódico La Voz de Madrid (18 de marzo de 1935):

"El modernismo no fue solamente una tendencia literaria (...) fue una tendencia general. Alcanzó a todo. Creo que el nombre venía de Alemania (...) Y aquí, en España, la gente nos puso ese nombre de modernistas por nuestra actitud. Era de nuevo el encuentro con la Belleza sepultada durante el siglo XIX por un tono general de poesía burguesa. Eso es el modernismo: un gran movimiento de entusiasmo y libertad hacia la belleza".

Este anhelo de belleza es inmortal y choca conflictivamente con las limitaciones del mundo y de la sociedad. Por eso, la coexistencia de una faceta de crítica política y social responde al deseo sincero de estos escritores de mejorar la realidad y trascender el estadio material para regenerar espiritualmente al propio individuo. Por tanto, más que una discutida oposición moderno-98, hay un solo y amplio movimiento, producto del cambio de sensibilidad, cuyos rasgos esenciales son tanto la rebeldía, la actitud de ruptura frente a lo "viejo", como la renovación del lenguaje en la poesía y la prosa. Así lo dirá Azorín en 1913: "Un espíritu de protesta, de 


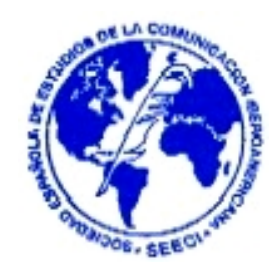

rebeldía, animaba a la juventud de 1898". Más que de una unidad compacta, hablaremos de un mismo magma en el que todos están inmersos: en 1900 ya había triunfado el modernismo, un año después de la llegada de Rubén Darío, encabezado por Juan Ramón Jiménez, y en él militaban personalidades muy diferentes, según recordará el poeta años después, prueba de la confusión reinante en estos primeros momentos y la dificultad de definir o limitar el nuevo modo de pensar:

"Cuando yo fui a Madrid a publicar mis primeros libros, no solamente oí llamar modernista a Rubén Darío, sino a Benavente, a Baroja, a Azorín y a Unamuno".

Dentro de este doble intento de renovación ideológica y estética podremos distinguir una actitud más preocupada y comprometida socialmente, "noventayochistas", o una actitud más estética y formalista, "modernista". Como señala Seoane, las dos tendencias inician la creación de revistas de vida precaria y efímera, en las que la rebeldía estética aparece al lado de la social, predominando en algunos casos una u otra. Esta distinción es la que a nosotros nos va a servir como delimitador de las revistas del 98 de las modernistas.

Este nuevo modo de pensar no estuvo exento de polémica: el enfrentamiento con los escritores de la generación anterior tuvo como escenario muchas veces las páginas de las revistas que nos ocupan. Un ejemplo de ello que nos aclara los posicionamientos respectivos de los escritores, lo encontramos dentro de Revista Nueva. En ella encontramos una crítica elogiosa de Baroja a otra revista significativa del momento, a saber, La Vida Literaria, originada en enero de 1899 tras un cisma surgido en el seno del viejo semanario Madrid Cómico. La primera, La Vida Literaria, pretendía abrir cauces a la inquieta y pujante juventud literaria sobre todo partidaria del modernismo, del que su director, Benavente (compartió por momentos la dirección con Clarín) era un entusiasta. Así publicó cuentos de Valle- Inclán y Baroja, poesías de Rubén Darío y teorías de Maeztu. Por ello la crítica de Baroja declarará: "Es uno de los semanarios madrileños que tienen originalidad y algo que no se 


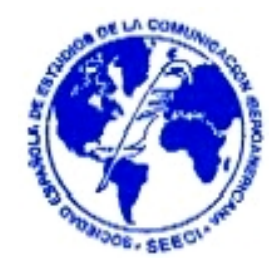

consigue con mucho dinero pensando sólo en entretener a la gente". Crítica velada al semanario humorístico Madrid Cómico, más popular, intrascendente y destinado a un público "mayoritario", que se convirtió en un bastión reaccionario desde el que se criticó severamente el modernismo y en especial a los del 98. Clarín a la cabeza, sin ir más lejos, había arremetido en sus "Paliques" de Madrid Cómico contra Maeztu, Rubén, Vallé-Inclán y el mismo Benavente, llamándolos "decadentes", "modernistas", "estetas", etc. Maeztu le responderá en el artículo significativo por su título Clarín, Madrid Cómico and C. Ltd., y que quejará de tales ataques, aceptando

"...las manos liliales, las torres ebúrneas, y demás letanías de nuestros pseudodecadentes, naturistas y estetas como un anhelo indefinido de otra literatura, como un preludio cuatrocentista de un Renacimiento...",

aunque sin solidarizarse con ellos, pues a Maeztu poco le interesan las posturas artísticas.

Pero es J uventud la revista que quizá mejor representa la preocupación por la nueva estética modernista y la polémica en todo su apogeo. Hay un fuerte interés por el estudio de las lenguas, sobre todo el vascuence (Unamuno había hecho sobre ella la tesis doctoral), relacionado con la vuelta al indigenismo propio del espíritu modernista. Hay que destacar a Manuel Machado con dos artículos. El primero, con título ya premonitorio, "El modernismo y la ropa vieja", reprocha a los viejos su miedo y su incomprensión hacia las nuevas formas, empezando por el mote:

"Modernista. La palabreja es deliciosa. Representa sencillamente el último gruñido de la rutina contra los pobres y desmedrados innovadores. De modo que aquí no hay nada moderno, pero hay modernismo. Y por modernismo se entiende... todo lo que no se entiende. Toda la evolución artística que de diez años, y aún más, a esta parte ha realizado Europa, y de la cual empezamos a tener 
vagamente noticia".

En el segundo, titulado "El arte y los artistas", comenta el discurso de Benlliure en la Academia de San Fernando, en el que había firmado cosas como "...el impresionismo es criminal... porque buscando las formas nuevas mata la verdad del arte...", para concluir con un tolerante

"...hay que acabar con esta raza de degenerados". Machado, por su parte, como afirma Palomo, resaltó las dos características más importantes definidoras del arte moderno: el individualismo del artista no sometido a otra norma que la de su propia personalidad y el arte entendido como valor absoluto. Incluso un Maeztu joven y rebelde, que como ya hemos apuntado estaba ajeno a esta nueva estética, quiso terciar en la polémica, no sin cierta brusquedad, en su artículo "Un día echado a perros":

"Observo que desde hace algún tiempo se ha recrudecido el odio inexplicable que inspira a ciertos escritores la tontería modernista. Allá se la hallan con esos modernófobos los jóvenes de los lirios, los nenúfares, las clepsidras y las walpurgis. Eso no va conmigo. Modernista de esa clase o antimodernista de la otra me inspiran las mismas ganas de hacer mis necesidades"

Nos interesa, por último, citar a Helios, aunque quizá ya no sea una revista propiamente del 98, pues el acento recae claramente hacia lo literario: considerada como la mejor revista del modernismo, con una presentación mucho más cuidadosa y organizada que las demás revistas fruto del ímpetu juvenil, es, en un sentido más estricto, la revista del modernismo poético. En carta a Rubén Darío, el mismo Juan Ramón, su principal artífice, explicó en proyecto de Helios:

"Querido maestro (...) cinco amigos y yo vamos a hacer una revista 


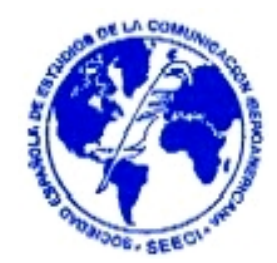

literaria seria y fina, algo como el Mercure de France: un tomo mensual de 150 páginas muy bien editado. Nosotros mismos costeamos la Revista (...) Nada de lucro: vamos a hacer una revista que se alimento espiritual; revista de ensueño; trabajaremos por el gran placer de trabajar".

Como señala Palomo, dos fueron los principios que guiaron la publicación: la búsqueda del ideal de belleza por encima de todo y la exaltación de la libertad. Por ello el magisterio de Rubén Darío fue fundamental y su concepto de la belleza se reitera con profusión y causa admiración. Leemos que Rubén ha pasado por la corte y la prensa ha silenciado su presencia: "La gente sigue ignorando quién es Rubén Darío (...) Rubén Darío es el poeta más grande que hoy tiene España". De aquí la importancia concedida al símbolo y a la revalorización de Góngora (por haber creado un lenguaje poético diferente al de uso común) en la famosa encuesta publicada en el tercer número, en la que se erige a Bécquer como el poeta más apreciado de nuestra tradición.

\section{La política y el problema de España.}

Después de los innumerables estudios escritos y la enorme bibliografía que se ha reunido sobre este tema, hoy día ya no nos extraña aceptar una visión del grupo del 98 lejana a la tópica imagen que ha quedado de ellos en la historia literaria, en la que destaca su interés por el paisajismo, los problemas metafísicos, existenciales, 0 en su espíritu agónico y escéptico. Después del libro de Blanco Aguinaga

" no parece ya hoy tan absurdo aceptar que Unamuno fue marxista por unos años, al igual que, a su modo, lo fue Maetzu, o que Azorín escribió seriamente en anarquista cuando se llamaba Martínez Ruiz".

Aunque acabaron luego renegando de esta actitud, es cierto que, en este momento que nos ocupa, entendieron "el problema de España" bajo la perspectiva de la lucha 


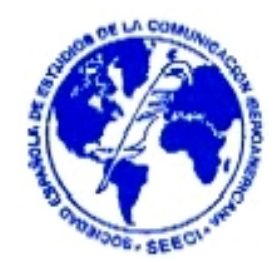

de clases, es decir, desde unas posiciones claramente afines a las de las organizaciones obreras anarquistas y marxistas de su tiempo.

Esto es así desde la primera publicación propiamente noventayochista, Germinal (1897-1899), en la que aparecen todos los escritores jóvenes, exceptuando a Azorín y Unamuno, mostrando un espíritu de rebeldía frente a los valores establecidos. Tanto el título, tomado de una novela de Zolá (folletón que publicará la revista en 1899), como el dibujo alegórico de Gustavo Doré en el número inicial, que representa "La Libertad" dirigiendo al pueblo armado, son expresión de este espíritu combativo. Como apunta María del Pilar Palomo, estos autores no concebían sólo la literatura como una cuestión de estética, sino que buscaban en ella transformar la sensibilidad social para acceder a un nuevo concepto de la justicia, del trabajo y de la solidaridad. Esto supone la continuidad con los afanes regeneracionistas y es la razón por la que, aunque la revista constituyese un instrumento de propaganda del partido socialista y su carácter fuese político-social, podamos encontrar entre sus páginas cuentos y poesías de Maeztu, colaboraciones de Baroja e, incluso aparece el Cuento color de sangre: El Rey de la Máscara, de Valle-Inclán, donde se da a conocer a "Bladamín", convertido por azar del tiempo y de la imaginación del autor en el Marqués de Bradomín. Curiosamente su director, Joaquín Dicenta, fue luego su más radical enemigo estético.

La postura progresista de la publicación se manifestará también en traducciones de autores extranjeros como Zolá, Víctor Hugo, Leopardi, Proudhomme, Renan, S. Rusiñol y A. Guiméra. Precisamente Germinal atenderá a los problemas políticos como los procesos de Montjuich, así como la situación de las cárceles o el anarquismo. Sin embargo casi no prestó ninguna atención al tema de las colonias, muestra del escaso interés que en las vísperas del desastre parece que tenía el tema. El anticlericalismo también fue un tema reiterado: siempre respetando a la religión en sí y el sentimiento religioso, los ataques iban dirigidos hacia el poder de la iglesia. En el fondo, el tema respondía a la tensión entre los valores tradicionales y el espíritu progresista, y el intento de armonizarlos entre sí como en el caso de Miguel 


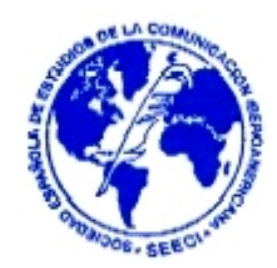

De Unamuno.

Muchos de sus redactores pasarán a integrar las filas de un periódico de gran alcance y difusión, El País, publicación de carácter progresista y de tono literario, fundando en 1887 como órgano del Partido Republicano Progresista de Ruiz Zorrilla, que acabó siendo un centro de reunión y un punto de encuentro de inestimable valor para el intercambio de ideas entre los escritores de la nueva hornada. Es aquí donde se conocieron, Maeztu, Baroja y Martínez Ruiz. Como muestra del espíritu crítico de éste último, señalaremos que fue expulsado del periódico al año siguiente de entrar (1897) por la violencia de sus artículos, lo cual nos da una idea de la agresividad de estos escritores. De él dirá Lerroux, que fue uno de sus directores, en sus memorias (recogido por María del Pilar Palomo):

"No es su mengua, sino en su elogio, recordaré que debutó rabiosamente radical, anarquista teorizante, hasta el punto de que alguna de sus colaboraciones provocó queja de nuestros lectores habituales".

Y De Maeztu afirma: "Un tanto parecido, con menos asiduidad en la colaboración, fue el De Maeztu, que no debutó ciertamente de conservador". Por su parte, Germinal pasó a subtitularse en lo sucesivo semanario "republicano-ideológico", haciéndose cargo de su dirección Salmerón. Entre sus redactores encontramos a Blasco I báñez y los primeros números tienen un acento más literario que en la época precedente. Poco después desaparecerá. Como escribió Rubén Darío:

"Las revistas independientes, producidas por el movimiento moderno, por las últimas ideas de arte y filosofía y de las que no hay país civilizado que no cuente hoy con una, o con varias, tuvo aquí su iniciación con Germinal, de filiación socialista, apoyada por lo mejor del pensamiento joven. Murió de extrema vitalidad quizá..." ("La cuestión de la revista La Caricatura", España Contemporánea, III, 


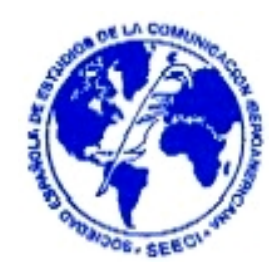

citado por Palomo, p. 292).

Este espíritu tiene su continuación en otra revista, Vida Nueva, nacida un mes después del Desastre, en la que Unamuno escribe dos conocidos artículos "Muera Don Quijote" y "Renovación", ejemplo característicos de la actitud iconoclasta de estos escritores jóvenes. Es conocido que Unamuno perteneció durante tres años (1894-1897) al partido socialista, aplaudiendo esta causa en los años cercanos al Desastre por creer en ella como alivio de miserias y portavoz de la verdad. Aunque se desengañó pronto, insistió en la utópica idea de cambiar al hombre, sobre todo al español, por lo que la prensa significó para él no sólo un medio fundamental para llevar a cabo su gran labor social y espiritual, sino algo más, el periodismo como apostolado: "seguramente me sentí ligado ya a mi pueblo para siempre, obligado a aleccionarle. Había empezado ya mi carrera de apóstol civil". El mensaje es claro en los dos artículos citados con anterioridad: se trata de hacer triunfar la evidencia de la realidad frente al idealismo de los sueños, encarnados en personajes de la tradición literaria española:

"España, la caballeresca España histórica, tiene, como Don Quijote, que renacer en el espiritu de Alonso el bueno, en el pueblo español, que vive bajo la historia, ignorándola en su mayor parte, por su fortuna. La nación española -la nación, no el pueblo- molida y quebrantada, ha de curar, si cura, como curó su héroe, para morir. Sí, para morir como nación y vivir como pueblo" (26 de junio de 1898).

"No creo que quede ya otro remedio que sumergirnos en el pueblo, inconsciente de la historia, en el protoplasma nacional, y emprender en todos los órdenes el estudio que Joaquín Costa ha emprendido en el jurídico. Hay que aprender a desengañarse de Segismundo, que soñó historia, y a vivir, del Alcalde de Zalaméa" (31 de julio de 1898). 


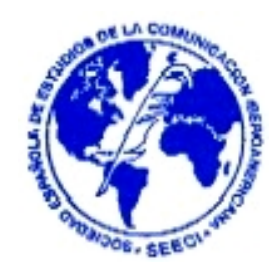

Vida Nueva dedica un número especial (el número 47) al primero de mayo al obrero español, con artículos de Pi y Margall, Nicolás Estévane, Dionisio Pérez y Santiago Alba, que reflejan el auge de las simpatías que los intelectuales toman por el socialismo. Incluso el jovencísimo Juan Ramón Jiménez se da a conocer al mundo literario a través de esta revista, con traducciones de poemas de Ibsen de tono anarquista y con creaciones poéticas propias, en las que, como elogiaba su director, Dionisio Pérez, mostraba su valentía hablando de la "tristeza de los menesterosos, de los explotados, de los humildes" "con impulsos de arrebatada ira". También están criticados en sus poemas los sucesos de Montjuich y los problemas sociales del momento, actitud combativa de crítica social que, como señala María del Pilar Palomo, fue constante en su dilatada labor poética y crítica, aunque transformada su expresión por el proceso de depuración poética que registra toda su obra, y que en este momento, como señalamos en la introducción, no representa sino el ambiente en que se vivía la renovación estética del fin de siglo, que utilizaba el arte y la belleza como armas de oposición al materialismo, positivismo y aburguesamiento de la sociedad.

Nos interesa volver a citar ahora Revista Nueva, para comprobar que, aunque todos coinciden en el mismo deseo de renovación, está claro que difieren en los métodos prácticos para conseguirlo, de aquí que podamos encontrar posturas radicalmente diferentes e incluso opuestas. Es el caso de Baroja y de Maeztu, obsesionado éste por el Desastre, por la moralización de la vida pública y por el ideal del resurgimiento, propone una solución pragmática y hasta amoral para cambiar la sociedad. Llega a decir en su artículo "En la Charca":

"...No hay literatura y no la hay porque no puede haberla, porque no debe haberla (...) No hay literatura porque primeramente necesitamos hacer patria, y las patrias no se hacen con la pluma, sino con el arado..."

Y en otro artículo, "La moral que muere y que nace", nos dice que los ambiciosos 


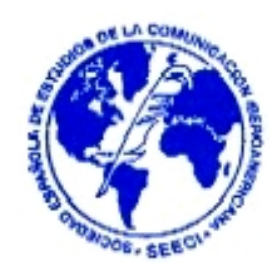

son quienes más engrandecen a los pueblos, dado que el dinero constituye el principio de las sociedades modernas: "El egoísta, por el contrario, realiza aun sin pretenderlo, una labor altruísta, respetable, patriótica".

Baroja, desde una posición idealista vecina al anarquismo, rechaza, en sus comentarios al libro de Maeztu Hacia otra España, este concepto de progreso por considerarlo antiestético y falto de espiritualidad. Como declara Seoane "...en sus artículos se muestra ya el Baroja individualista, feroz, pesimista, iconoclasta, dogmatófobo y propenso al exabrupto".

"Maeztu ... nos trae sus entusiasmos anglosajones y nietzscheanos por la fuerza, por el oro, por las calles tiradas a cordel, y a nosotros nos enternece la debilidad, la pobreza y las callejuelas tortuosas, oscuras $y$ en pendiente. Nos canta Bilbao, a nosotros que no pensamos más que en Toledo y en Granada, y que preferimos el pueblo que duerme al pueblo que vela (...). Por más que llame bufo al desaliento, el desaliento existe, algo peor, la indiferencia; por más que sueñe con otra España, la otra España no vendrá, y si viene será sin pensarlo ni quererlo, por la fuerza fatal de los hechos (...) Yo que no pienso, y casi podría añadir que ni quiero, ser nada en la vida, miro a Maeztu como un paralítico podría mirar a un gimnasta; me asombra su decisión, su acometividad, su entusiasmo y su fuerza, pero no le sigo. Es más, el día en que esa Nueva España venga a implantarse en nuestro territorio con sus máquinas odiosas, sus chimeneas, sus montones de carbón, sus canales de riego; el día en que nuestros pueblos tengan las calles tiradas a cordel, ese día emigro, no a Inglaterra o a Francia (...), a Marruesco o a otro sitio donde no hayan llegado esos perfeccionamientos de la civilización".

Y es que, como recoge María del Pilar Palomo, Revista Nueva se ocupa más del aspecto ideológico: preocupan más los planteamientos espiritualistas que los 


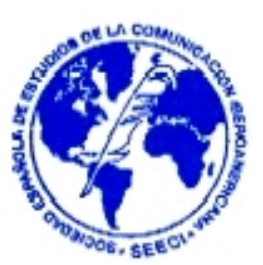

materiales y hay una cierta acusación a la sociedad moderna, sólo preocupada por el progreso material, y a la ciencia, como causantes de esta infravaloración de lo espiritual. Parecido sentido tiene otro artículo de Baroja, mal comprendido por su título, "Contra la democracia", en el que critica a la masa a favor del individuo, siempre relegado en cualquier democracia política para quien sólo cuenta el número: "la que tiende al dominio de la masa y que es un absolutismo del número". Incluso es posible poner en duda el "regeneracionismo" de Baroja en este momento, pues de la guerra colonial de 1898 no hay en la prensa la huella que cabría imaginar en el tópico del Baroja noventayochista, al contrario, su escepticismo, de nuevo, es bastante revelador:

"Oír regeneración y escamarme es todo uno. Es una palabreja que está en boga. Para Sagasta significa estar en el poder; para Silvela, llegar a probarlo, y para Weyler, hacer del país un cuartel. El único regeneracionista que tenemos en España es... Eusebio Blasco" (se refiere al escritor de veta bastante cómica).

$Y$ es que en estos momentos iniciales la labor de los noventayochistas es mejor entenderla como emparentada con los movimientos políticos revolucionarios y con la actitud de rebeldía que ello implica, más que desde la cercanía a los escritores regeneracionistas. En el fondo, lo que Baroja predica es la autenticidad por encima de todo y quiere contraponer un escepticismo auténtico por la política formal del país a un falso escepticismo "que viene a ser la señal de los tiempos".

Unamuno, conciliador entre aquellas posturas extremas de Maeztu y Baroja, se decante por la solución intermedia, como señala María del Pilar Palomo, al aceptar el progreso material siempre que sirva de medio para conseguir la emancipación espiritual e intelectual del hombre. En Revista Nueva encontraremos un Unamuno ejemplo del espíritu de la época, que era capaz de repartir su alma entre la contemplación y la batalla, entre la melancolía y la denuncia, pues está representado en sus dos facetas, como batallador del regeneracionismo intelectual en sus 


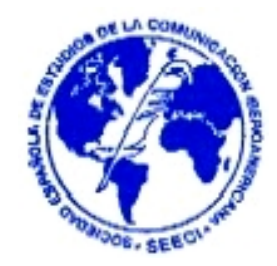

artículos. De la enseñanza superior en España, y como lírico intimista en comunión con la naturaleza en los poemas: "El Cristo de La Cabrera" y "La flor tronchada", éste último muestra de un sincero optimismo cristiano.

Merece la pena reseñalar la revista Electra (1901), nacida mes y medio después del estreno con clamoroso éxito y no menor escándalo del drama galdosiano del mismo nombre. Planteada como un grito de rebeldía contra el clericalismo en cuanto forma de castigar la inocencia espontánea, como sucede en el personaje de Galdós, representó la rebelión contra las formas impuestas y el impulso sincero de romper contra todo fanatismo, lo que explica el tono combativo y el espíritu iconoclasta de sus colaboradores. A pesar de su corta existencia, pues tan sólo sacó seis números, su presencia tuvo un peso destacado en la ideología del momento, pues representó la postura más crítica de los jóvenes que trataban de aunar las aspiraciones estéticas con las inquietudes sociales.

Aunque ya se conocían desde su participación en El País, como ya dijimos, es a causa del acontecimiento del estreno y del contacto que mantuvieron en la revista desde donde surgió el lazo de unión entre Baroja, Maeztu y Martínez Ruíz, quienes al final del año firmaron el famoso "Manifiesto de los Tres". El mismo Baroja, que siempre intentó negar la existencia de la generación del 98, lo reconocería en sus Memorias:

"Si hubo algo como un grupo literario, que duró lo que un relámpago, y tuvo como acto de nacimiento con su fecha, fue el estreno de Electra en 1901. Entonces se intentó formar un grupo para constituir una redacción de una revista con el mismo título, pero el invento fracasó y no pudo llegar a tener tres personas reunidas y amigas ni a sostener la revista".

Juventud (1901-1902) es, junto con Alma Española, a juicio de Gómez Aparicio, el mejor exponente de lo que el regeneracionismo quiso representar, pues nos va a 


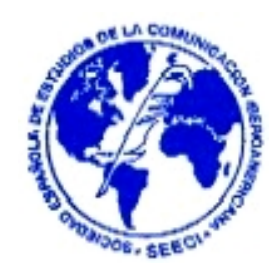

mostrar claramente la tensión entre sus ideales situados entre la tradición y la europeización: en la misma línea que Germinal, pretendía una tarea constructiva que sirviera para conseguir el progreso a partir de lo genuinamente hispánico, desde el artículo de su primer número "España por siempre": "Nuestro deseo es hacer labor nacional, estimular energías latentes en nuestro país, donde tantos son a disolver, a desacreditar, y tan pocos a hacer labor constructiva".

Esta postura, que ya había defendido Unamuno es sus artículos de Revista Nueva (De la enseñanza superior en España) y Ganivet (en su Idearium) era una clara resonancia del espíritu institucionalista defendido por Giner y el krausismo, en el que se había formado la juventud del 98. Como vemos en un artículo a modo de manifiesto, titulado Los nuevos rumbos:

"¿Quién duda que el espíritu nacional, al nutrirse con las nuevas ideas, no ha de modificarse, transformándose grandemente? $Y$ es ciertamente indudable que la transformación ésta ha de tener por fundamento y base de desenvolvimiento aquello que nuestra alma tenga de particular, de característico, de propio y exclusivo suyo, y que ha de fecundarse con los gérmenes nuevos que sobre ella caigan".

Así se propone, para "fomentar el desarrollo de la personalidad hispana", ahondar en el estudio de nuestro pasado con la finalidad de conocer mejor el presente y llegar a conocer mejor las causas reales de nuestro atraso y ponerlas remedio. Costa lanza sus consignas: "El gran problema español es el de nivelarnos con Europa". Y, como recoge Seoane, el editorial del número cinco, titulado "Con rumbo fijo", insiste en esta necesidad: partiendo

"la propia y firme convicción de la realidad de nuestro atraso, de la evidencia de la lentitud y de la torpeza de nuestra marcha por la senda progresiva, que con tan vertiginosa rapidez recorre el resto de 


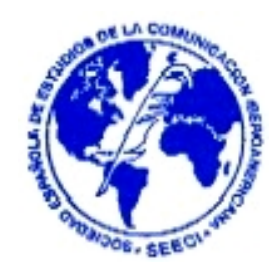

Europa (...) hacer el estudio de España, casi desconocida e ignorada", con objeto de conocer "qué es lo que necesitamos de lo moderno, como debemos adaptarlo y aplicarlo".

Por eso se presta atención a nuestras costumbres y a la moral, como Baroja, que interpretado a menudo como anarquista defiende, en su artículo "Mi moral", su individualismo con rebeldía frente a los códigos impuestos por la masa como forma de comportamiento, con clara influencia del vitalismo nietzscheano:

"No soy anarquista. Soy un individualista rabioso, soy un rebelde: la sociedad me parece defectuosa porque no me permite desarrollar mis energías, nada más (...) Mi noción central de la moralidad es ésta: todo precepto moral que ayude a la evolución, es bueno; todo precepto que lo dificulte, es malo".

Otro tema fundamental va a ser la educación, pues no hay progreso sin instrucción: se proponen cambiar los presupuestos destinados a la enseñanza, fomentar las becas para el extranjero para abrir el camino de la europeización de España, y así lograr el vergonzoso número de analfabetos (66\% en 1900).

El grupo inicia una nueva publicación después de concluida la revista Juventud, se llamará Alma Española (1903-1904). Para algunos es quizá la más genuina creación de los hombres del 98 (Sánchez Aranda), pues es la que expresa mejor su espíritu común. Su mayor éxito fue convertirse en bandera de esperanza en la ilusión de forja de una Nueva España, audacia renovadora que fue correspondida por el público a decir de la propia publicación, pues llegó a tirar sesenta y ocho mil ejemplares, cifra astronómica entonces (y ahora para una revista de semejante contenido). En efecto, el título (al que servía como fondo, en sus colores, la bandera nacional) respondía a la reiterada petición de los intelectuales de indagar "el alma castellana" (como Unamuno en "En torno al casticismo" en 1805) o en el "alma nacional" (como Ganivet en su Idearium español) para escudriñar la esencia española, con vistas a 


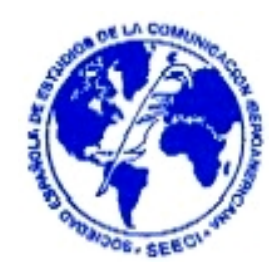

reaccionar contra el pesimismo dominante y levantar el espíritu de la nación de entre sus cenizas, tal como expresa esperanzadoramente desde el primer número Galdós en su conocido "Soñemos, alma, soñemos":

"El pesimismo que la España caduca nos predica para prepararnos a un deshonroso morir, ha generalizado una idea falsa. La catástrofe del 98 sugiere a muchos la idea de un inmenso bajón de la raza y su energía. No hay tal bajón, ni cosa que lo valga".

En esta línea la publicación acometió dos ensayos. El primero de ellos, iniciado ya en el segundo número, fue el de plantear cara a la opinión nacional el problema que contenía esta pregunta "A su juicio ¿dónde está el porvenir y cuál debe ser la base del engrandecimiento de España?" Encuesta a la que contestaron las principales personalidades representativas de todas las Instituciones, desde la política, como Silvela, Eduardo Dato, Salmerón o Joaquín Costa, hasta la literatura, como la condesa de Pardo Bazán, Blasco Ibáñez o Unamuno, pasando por la ciencia (Ramón y Cajal) y el periodismo (José Ortega Munilla). El segundo ensayo fue divulgar la verdadera realidad nacional, para lo que contaba con una sección fija dedicada a reflejar el "alma" de las regiones, pues España es para ellos una unidad fecunda nacida de una variedad armonizada y, por tanto, el "alma española" no sería otra que la suma de las "almas" dispersas, que aisladas morirían, así como su unidad. Colaboraron Unamuno ("alma vasca"), Maragall ("alma catalana"), Pardo Bazán ("alma gallega"), Pereda (uno de los "viejos", retrató el "alma montañesa"), Blasco Ibáñez ("alma valenciana"), etc.

Aunque en Helios también están presentes las preocupaciones sociales y la preocupación por España, no tienen la agresividad de otras revistas, sino que más bien son reflexiones generales que tratan de proclamar por encima de todo "la universalidad como ideal de la humanidad". Con este pensamiento, de clara herencia krausista, Helios muestra otro talante distinto, que se corresponde con la nueva actitud que Rubén elogió en su segundo viaje a España: 
"... esparcí entre la juventud los principios de libertad intelectual y de personalismo artístico que habían sido la base de nuestra vida nueva en el pensamiento y el arte de escribir hispanoamericanos, y que causaron allá espanto y enojo entre los intransigentes. La juventud vibrante me siguió y hoy (1912) muchos de aquellos jóvenes llevan los primeros nombres de la España literaria".

Con ello nuestro itinerario ha concluido, pues aunque nacieron otras revistas como Nuevo Mercurio (de enero a diciembre de 1907) o Renacimiento (fundada en marzo de 1907), estas corresponden a la plenitud del modernismo, recayendo su peso en lo poético, lo puramente literario frente a la preocupación por el "problema de España". Los (ya) hombres del 98, que habían valorado siempre mejor sus colaboraciones en las revistas que las realizadas para prensa diaria, la prensa de "gran información", acabaron emigrando a ésta y dispersándose, como sugiere Gómez Aparicio. Maeztu ingresó en La Correspondencia de España, que le envió a Londres como corresponsal. J osé Martínez Ruiz y Pío Baroja se incorporaron a El Globo, que envió a este último en 1903 a Tánger como enviado especial, para cubrir la rebelión que había estallado en Marruecos. 


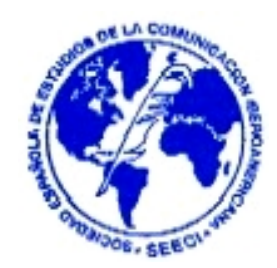

\section{Bibliografía.}

BLANCO AGUINAGA, Carlos (1998): Juventud del 98. 3a ed. Taurus. Madrid.

BLEIBERG, Germán (1948): Algunas revistas literarias hacia 1898 en Revista Árbor: revista general de investigación y cultura. Tomo XI, № 36, diciembre.

DE TORRE, Guillermo (1941): La Generación española de 1898 en las revistas del tiempo en Nosotros, Tomo XV, № 67, octubre 1941. Buenos Aires.

GÓMEZ APARICIO, Pedro (1967): Historia del Periodismo español. T. 3: de las guerras coloniales a la Dictadura. Editora Nacional. Madrid.

MOLINA, César Antonio (1990): Medio siglo de prensa literaria española (19001950). Endymion. Madrid.

PALOMO, María del Pilar (ed.) (1997): Movimientos literarios y periodismo en España. Síntesis. Madrid.

PIZARROSO QUINTERO, Alejandro (1992): De la Gazeta Nueva a Canal Plus. Complutense. Madrid,

SÁNCHEZ ARANDA, José y BARRERA DEL BARRIO, Carlos (1992): Historia del Periodismo Español: desde sus orígenes hasta 1975. Ediciones Universidad de Navarra. Pamplona.

SEOANE, María Cruz y SÁlZ. María Dolores (1996): Historia del pensamiento en España. Vol. 3. El siglo XX, 1898-1936. Alianza. Madrid.

TOBAJAS, Marcelino (1984): El periodismo español: notas para su historia. Forja. Madrid. 